\title{
ORDEN INTERNO Y POLÍTICA EXTERIOR ARGENTINA: LA CUESTIÓN DE LOS BIOCOMBUSTIBLES
}

Cristian Lorenzo ${ }^{1}$

\section{Introducción}

Este trabajo contribuye a la comprensión de la política exterior argentina reciente, focalizando en el estudio de su orden interno. Para ello, se analiza cómo se fue configurando el apoyo político doméstico de la política exterior argentina hacia América Latina, en materia de biocombustibles.

El estudio de las interrelaciones entre el ámbito doméstico y las relaciones internacionales registra amplios antecedentes en Estados Unidos como en Europa (Gourevitch I978; Putnam i988; Duroselle i998). En América Latina, también se abordó este fenómeno tanto desde el punto de vista teórico como empírico. Hay un interesante aporte de van Klaveren, en este sentido, en el que realizó una clasificación de los enfoques teóricos generalmente utilizados. Si bien planteó que no había un consenso sobre cuál era la variable que más poder explicativo tenía, señaló que los comportamientos de política exterior, generalmente, eran considerados a partir de sus factores internos y externos (van Klaveren I984).

En Argentina, el fenómeno de la política exterior fue analizado, señalando una retroalimentación permanente entre el ámbito internacional y el interno. Por ejemplo, Figari señaló que: "si la política exterior de una nación está inserta en un contexto internacional determinado que influye sobre sus ámbitos culturales, políticos, sociales y económicos, no es menos cierto

\footnotetext{
I Licenciado en Relaciones Internacionales (Universidad del Salvador), magíster en Ciencia Política y Sociología (Flacso, Argentina) y doctor en Relaciones Internacionales (Universidad del Salvador). Es becario posdoctoral del Consejo Nacional de Investigaciones Científicas y Técnicas de Argentina (Conicet). Afiliación institucional: Centro Austral de Investigaciones Científicas (Cadic) - Conicet, situado en la ciudad de Ushuaia, Argentina. E-mail: clorenzo.ar@ gmail.com.
} 
que la política exterior, dentro de esos límites impuestos por el contexto internacional, también constituye la manifestación de los objetivos -valores e intereses- que la Nación pretende promover en el mundo" (Figari I993, 43). Cabe agregar que este autor distingue dos fases, una interna y otra externa, lo que permite ordenar los elementos principales de la cita referida. Dice: "toda política exterior tiene dos fases. Una es la faz interna que informa sobre los recursos que tiene la Nación, para promover sus valores e intereses en la faz externa" (Figari I993, 44).

Ana Seitz, por su parte, planteó que la política exterior "lejos de ser solo una política burocrática, es la resultante de un vector dinámico de fuerzas y presiones que se ejercen desde dentro de los países y desde el sistema internacional en su complejidad y que termina por ser sintetizada en las decisiones burocráticas aludidas" (Seitz 20I0, 2). Con esta definición, esta autora agregó la idea de "duraciones" de los fenómenos, en sintonía con el planteo de la escuela de los Anales.

Para este trabajo, interesan particularmente aquellas investigaciones que enfatizaron en el orden del interno como causas de la política exterior de Argentina. En este punto podría realizarse una distinción. Algunos, se focalizaron en la influencia de actores domésticos en la política exterior. Un ejemplo de ello, puede encontrarse en el trabajo de Roberto Miranda, quién analizó la formulación de políticas destinadas al Mercado Común del Sur (MERCOSUR) en el período I995-20II. Este autor concluye, en primer lugar, que la política doméstica no influenció relevantemente en la formulación de políticas en este ámbito de integración regional. En realidad, observó que los actores subestatales y no estatales de la vida política argentina no fueron incluídos en el proceso de toma de decisiones del Ejecutivo. Para Miranda, no había articulación entre el Ejecutivo y la Cancillería, por un lado; y actores subestatales y no estatales, por el otro. Esta desconexión descansaba, en definitiva, en una característica que permanece en el tiempo en Argentina: las decisiones externas están concentradas en el Ejecutivo (Miranda 200I).

También, hay trabajos que focalizan más en el contexto del orden interno y no sobre el comportamiento de actores, específicamente. A modo de ejemplo, Anabella Busso observó que en Argentina la política exterior es la política pública más cambiante desde la vuelta a su democracia. Su devenir no ha dependido tanto de variables sistémicas sino que ubica sus causas en el orden interno. Afirmó esta autora: "las principales causas que explican los vaivenes de la política exterior en democracia son las crisis político/económicas, las tensiones entre los distintos modelos de desarrollo y sus respectivas estrategias de inserción internacional y las variaciones en la concepción de democracia" (Busso 20I4). 
En el marco de estas interpretaciones, se sostiene que el apoyo político doméstico fue uno de los pilares de la política exterior argentina hacia América Latina en biocombustibles, durante los gobiernos de Néstor Kirchner (2003-2007) y Cristina Fernández (2007-20II). En función de esta afirmación, primeramente se presentan algunas características del contexto histórico del sector de la agroindustria en Argentina. Posteriormente, se aborda cómo fue posible obtener el apoyo político doméstico, a partir de la existencia de intereses en confrontación. Para ello, se analiza las posiciones de actores en el Congreso Nacional en la discusión sobre un proyecto presentado por el Senador Luis Falcó de la Unión Cívica Radical, que proponía promover el desarrollo de la producción de biocombustibles en Argentina. Luego, se analiza el posicionamiento del Instituto Nacional de Tecnología Industrial (INTI) y el Instituto Nacional de Tecnología Agropecuaria (INTA) en torno de la dimensión ambiental del modelo de desarrollo de biocombustibles de Argentina, su vinculación con otros actores y sus percepciones sobre las tendencias internacionales. Por último, se presenta la política exterior argentina en biocombustibles hacia América Latina.

\section{Exportaciones, política agropecuaria y ciencia}

En materia de comercio exterior, según datos de la Cámara Argentina de Biocombustibles, entidad que nuclea los intereses de las principales empresas exportadoras de este tipo de energía en Argentina, Argentina ha mantenido un crecimiento constante y significativo de sus exportaciones en biocombustibles, tal como se señala en la Tabla I. Si se compara el año 20II con el 2007, estas exportaciones crecieron en un rooo por ciento.

Tabla I - Exportaciones de Biodiesel de Argentina en toneladas

\begin{tabular}{|l|c|c|c|c|c|} 
& 2007 & 2008 & 2009 & 2010 & 2011 \\
\hline Totales & 168.364 & 724.792 & 1.149 .663 & 1363.506 & 1.692 .891 \\
\hline
\end{tabular}

Fuente: Cámara Argentina de Biocombustibles, 2014

Este es un sector, concentrado en empresas con capacidad de producción a grandes escalas, que recibió inversiones de empresas de origen nacional y extranjeras. En la tabla 2, se señalan la presencia de empresas internacionales en el sector: 


\begin{tabular}{|c|c|c|}
\hline Empresa & Grupo & $\begin{array}{l}\text { Capacidad de } \\
\text { Planta } \\
\text { (tn/año) } 2010\end{array}$ \\
\hline Renova S.A. & $\begin{array}{l}\text { Grupo Pérez Companc (Argentina), Grupo } \\
\text { Glencore (Suiza); Grupo Vicentín (Argentina) }\end{array}$ & 480.000 \\
\hline $\begin{array}{l}\text { LDC Argen- } \\
\text { tina S.A }\end{array}$ & Grupo Louis Dreyfus (Francia) & 240.000 \\
\hline Ecofuel & $\begin{array}{l}\text { Grupo AGD (Argentina); Bunge Limited (Esta- } \\
\text { dos Unidos) }\end{array}$ & 240.000 \\
\hline Cargill & Cargill (Estados Unidos) & 240.000 \\
\hline Explora & Grupo Meck (Chile) & 120.000 \\
\hline
\end{tabular}

Para situar en un contexto más amplio la tendencia de este sector de la economía, se toma como referencia el año 20ı, un año antes del final del período de estudio de este trabajo, para tener una visión global de cómo era la estructura de sus exportaciones de Argentina. Si se consideran las exportaciones por grandes rubros, las exportaciones de origen agropecuario $(33,3 \%)$ estaban levemente por debajo de las de origen industrial (35\%). Concentrándonos en el primer componente, el complejo más relevante fue el oleaginoso, con una participación estimada del 25\% (I3.963.732 de dólares) de las exportaciones totales argentinas (55.672.097 de dólares). Esto señala la importancia para la economía argentina y también, la existencia de una alta disponibilidad de aceite de soja, materia prima para producir biocombustibles en Argentina. Si dicho aceite se vendía directamente en el mercado internacional o se lo transformaba en biodiesel, dependía del precio internacional y de factores internos, como ser el cobro de derechos de exportación del estado argentino.

Asimismo, es necesario presentar dos aspectos adicionales: las exportaciones del sector oleaginoso provenían principalmente de la provincia de Santa Fe, ubicada en el sector litoral del país (Instituto Nacional de Estadísticas y Censos, 2010). A esta concentración geográfica de la producción se añadía que dichas exportaciones estaban concentradas en pocas empresas de una capacidad de producción a grandes escalas, tales como Cargill, Noble Grain, ADM y Bunge (Marín, Ana; Pérez Constanzó, Gloria. 20II, 20II, 22).

En política agropecuaria, las relaciones del gobierno con el campo transitaron coyunturas de una intensa conflictividad política. La introducción de retenciones a las exportaciones agropecuarias, mediante la Resolución I25/2008 durante el mes de marzo de 2008 representó una quita de las ga- 
nancias al sector rural, lo que produjo una serie de paros en distintos puntos del país. Esa medida estuvo vigente hasta el mes de julio, cuando finalmente se derogó. En el período transcurrido los sectores que representan intereses del sector agropecuario lideraron distintos paros y movilizaciones en el país. En el ámbito de los biocombustibles, la resolución I26/2008 incrementó el volúmen de retenciones a un $20 \%$. Aún hoy, este es un tema sensible para el sector porque afecta a sus ganancias.

Cabe añadir que en este contexto de confrontación entre el Gobierno nacional y las entidades representantes de intereses del sector agropecuario, la Secretaria de Ambiente y Desarrollo Sustentable arremetió contra los intereses del sector agropecuario. Publicó un informe concluyendo que: "La expansión de la soja representa una reciente y poderosa amenaza sobre la biodiversidad de Argentina ... La producción de sojas resistentes a los herbicidas conlleva también a problemas ambientales como la deforestación, la degradación de suelos, polución con severa concentración de tierras e ingresos, expulsión de la población rural a la frontera amazónica o áreas urbanas, fomentando la concentración de los pobres en las ciudades" (Secretaría de Ambiente y Desarrollo Sustentable, 2008).

Esto tuvo repercusiones en el ámbito científico. Durante el mes de abril de 2009 , las conclusiones a las que había arribado el Dr. Andrés Carrasco, investigador del Consejo Nacional de Investigaciones Científicas y Técnicas (CONICET), suscitó polémicas. Su crítica apuntaba a los efectos del glifosato a la salud humana. Esta iba en contra de los cimientos de un modelo agropecuario cuya productividad estaba influenciada por el uso de este herbicida. Esto dijo dicho investigador:

Se utilizaron embriones anfibios, un modelo tradicional de estudio, ideal para determinar concentraciones que pueden alterar mecanismos fisiológicos que produzcan perjuicio celular y/o trastornos durante el desarrollo. Y debido a la conservación de los mecanismos que regulan el desarrollo embrionario de los vertebrados, los resultados son totalmente comparables con lo que sucedería con el desarrollo del embrión humano (Página I2, I3 de abril de 2009).

Días más tarde, el Ministro de Ciencia y Tecnología argentino, el Dr. Lino Barañao, fue entrevistado por Héctor Huergo, un periodista con larga trayectoria en el ámbito rural y que estaba a favor del desarrollo de biocombustibles en Argentina. En el programa “El campo, la industria verde”, dijo: 
Tal vez habría que relativizar un poco estos resultados porque no son directamente extrapolables a lo que podría ocurrir en la situación de campo, es decir, que una sustancia puesta en contacto directo con un tejido puede tener efectos que no se verifican cuando esto se da en condiciones ambientales normales. Por otra parte, existe otra cantidad de estudios en el mismo sentido de exposición de células animales a distintas sustancias usadas que evidencian un efecto pero eso no es, repito, no es directamente extrapolable. Lo que sí creo es el aspecto positivo, es justamente recalcar que no hay sustancias inocuas, que hay que tener los recaudos necesarios para la manipulación de cualquier producto que se usa (La Política On Line, I de mayo de 2009).

Sus declaraciones, claramente, significaron un respaldo al rumbo que había tomado la política agroindustrial del gobierno argentino. Esto fue ratificado mediante un informe elaborado por un Consejo Científico Interdisciplinario creado en el ámbito del CONICET. No puede dejar de al menos mencionarse que los cuestionamientos al modelo dominante agrícola-exportador también venían de organizaciones no gubernamentales. Como contracara de este proceso del modelo agropecuario exportador, había actores domésticos críticos al modelo "sojero" de Argentina. El Grupo de Reflexión Rural era uno de ellos, quienes promovían la campaña "Paren de Fumigar". Como producto de los testimonios recolectados en distintos puntos del país, esta organización publicó en el 2009 el libro "Pueblos Fumigados. Los efectos de los plaguicidas en las regiones sojeras", denunciando las consecuencias sobre la salud humana del glifosato (Rulli 2009).

\section{Discusiones en el Congreso de la Nación}

En junio de 2004, el Senador Luis Falcó del partido Unión Cívica Radical presentó un proyecto de ley, con el nombre de "Régimen promocional para la investigación, desarrollo, generación y uso de los biocombutibles y derivados oleoquímicos". Esta no era la primera vez que en el Congreso de la Nación se presentaba un proyecto referido a biocombustibles, pero a diferencia de los anteriores, este proyecto prosperó y terminó convirtiéndose en ley. Cuando el Senador Falcó presentó su proyecto contó con el apoyo de 49 Senadores, pertenecientes a distintos partidos y provincias. Esto generó expectativas en altas esferas del poder. De hecho, el 3 de julio, el Vicepresidente de la Nación en ejercicio publicó un artículo en el diario Clarín destacando la importancia estratégica que esta política tenía. Esto permite calibrar la relevancia política de los biocombustibles. Su apoyo provenía del Vicepresidente 
de la Nación, miembro del partido político gobernante y opositor, quién afirmó: "Puede decirse que nos encontramos ante una iniciativa de envergadura estratégica, que cuenta con el consenso político suficiente como para colocar a la producción de biocombustibles en el lugar de una de esas grandes políticas de Estado que la Argentina necesita para forjar un porvenir venturoso para todos" (Scioli 2004).

El I de diciembre, el Senado dio media sanción al proyecto presentado por el Senador Falcó y giró este proyecto a 6 comisiones de Diputados. La última de las comisiones que presentó su dictamen fue la de Presupuesto y Hacienda, con modificaciones sobre sus aspectos fiscales e impositivos. Después de sancionarse el 22 de marzo de 2006 , este proyecto pasó nuevamente a Senadores, hasta que quedó sancionada como ley el ig de abril, con el nombre de "Régimen de regulación y promoción para la producción y uso sustentable de biocombustibles”. Finalmente, se reglamentó en febrero de 2007.

En esta sección, se analiza las posiciones de actores en el Congreso Nacional respecto de la posibilidad de regular la producción y consumo de biocombustibles en Argentina. El período de estudio se restringe al transcurrido desde que Falcó presentó el referido proyecto hasta su reglamentación. Y para ello, se aborda un dilema que transversalmente recorrió a las discusiones legislativas: ¿había o no que otorgar beneficios e incentivos al desarrollo de esta industria? Como parte de la puja de interés, el Secretario de Agricultura, en una publicación del diario Clarín en octubre de 2004, marcó claramente su posición, que afectaría directamente al surgimiento y despliegue del sector de los biocombustibles:

Probablemente, antes de fin de año contemos con la media sanción de un proyecto de ley de biocombustibles, para continuar su tratamiento legislativo el próximo año. Así, contaríamos con un proyecto de ley nacional, que prevea como mínimo la estabilidad fiscal a diez años para los futuros inversores en el sector, el corte obligatorio de gasoil y naftas con biodiesel y etanol al $5 \%$, la liberación en el IVA para los proyectos que califiquen ante la Autoridad de Aplicación, como instrumento fiscal imprescindible para suavizar el diferencial de precio actual entre los combustibles fósiles y los biocombustibles puros, y el fomento público al desarrollo de este nuevo sector (Campos 2004).

De la misma forma, otro actor clave en este proceso fue la Asociación Argentina de Biocombustibles e Hidrógeno (AABH). Desde esta organización se subrayó los beneficios tanto sociales, ambientales como económicos que se desprenderían de aquella industria que estaba en sus momentos ini- 
ciales de gestación. En este sentido, se destacó la importancia del componente fiscal e impositivo para su desarrollo:

Sin incentivos fiscales no es posible construir una oferta permanente de biocombustibles que se ajusten a un estándar de calidad óptimo. Por ello, a priori se plantea la cuestión del costo fiscal que dichos incentivos generan. Esta cuestión se torna relevante en países como Argentina, muy sensibles a la situación tributaria. Sin embargo, en cuanto se profundiza el análisis, surgen conclusiones sorprendentes (Molina 2004).

En el ámbito legislativo, dentro de los que estaban a favor de sancionar una ley para los biocombustibles encontramos que en el caso del Senador Urquía se dio la particularidad de además de pertenecer a un partido político oficialista con representación en el Congreso, era Presidente de una aceitera importante en Argentina. "Sin incentivos fiscales no es posible construir una oferta permanente de biocombustibles que se ajusten a un estándar de calidad óptimo" (Urquía 2005), afirmó contundentemente en una publicación realizada en el suplemento Rural del diario argentino Clarín. Este dato era fundamental porque manifiesta el interés del sector aceitero en posicionar a los biocombustibles como una alternativa energética en el país porque representaban una demanda adicional a sus productos. Un dato a tener en cuenta es que, una vez sancionada la ley de biocombustibles, puede observarse que la empresa que presidía -Aceite General Deheza- obtuvo de la Secretaría de Energía, una habilitación para comercializar su producción de biocombustibles en el mercado interno. Por más que su designación haya sido de acuerdo al procedimiento burocrático definido para tal motivo, dejaba poco claro dónde estaban los límites de la representación de intereses.

Frente a los aspectos fiscales e impositivos en cuestión, la Cámara Aceitera de la República Argentina (CIARA), envió una nota directamente a la Cámara de Diputados cuestionando el otorgamiento sin restricciones de beneficios fiscales e impositivos:

Finalmente cabe plantearse que si con todos los beneficios que el proyecto de ley establece ... los proyectos que se presenten no son viables económicamente, entendemos que entonces habría que repensar el tema con una evaluación más exhaustiva de los beneficios que se desprenderán de los mismos y eventualmente si se llegara a la conclusión de que es necesario un aporte adicional, éste debiera originarse en un desembolso en forma de subsidio explícito por la real diferencia que requiera la viabilidad del proyecto (Clarín 2005).

En esta puja por incluir o excluir beneficios fiscales e impositivos, se 
destrabó finalmente con el dictamen de la Comisión de Presupuesto y Hacienda del Congreso. Esta Comisión solicitó hacer una serie de cambios al proyecto para acotar el costo fiscal que traería para el país (Cronista.com 2006). En realidad, no solicitaba eliminarlos sino restringirlos. En un informe que la Asociación Federal de Ingresos Públicos envió a Diputados se expidieron de la siguiente forma:

Se estima inconveniente la implementación de este tipo de beneficios, entendiéndose mucho más apropiado el otorgamiento de subsidios directos a los sujetos que realicen las actividades que se intentan fomentar, siendo este último mecanismo más transparente y de mucho más fácil control, sin desvirtuar el régimen impositivo vigente (Clarín 2005).

Como resultado de las negociaciones, predominaron finalmente los intereses del Ministerio de Economía, por sobre aquellos que sí querían incluir en el proyecto, beneficios fiscales e impositivos. En este sentido, algunos legisladores del Senador manifestaron su oposición a las reformas de Diputados. Según el Senador Falcó, quien había presentado el proyecto originalmente, "desde el punto de vista de la forma le han cambiado hasta el título". Esto no era una cuestión cosmética, lo que reflejaba era una serie de cambios, producto de intereses en juego.

Nosotros hablábamos de un proyecto de investigación y de desarrollo de la industria de los biocombustibles y sus derivados; y la Cámara de Diputados lo tituló como un régimen de regulación y de promoción, que finalmente - a nuestro juicio - fue una seudo promoción de la industria de los biocombustibles. Esto habla un poco de la intencionalidad de los cambios estructurales del proyecto, ya que hasta su título fue cambiado sustancialmente (Cámara de Senadores de la Nación 2006, I3).

Este proyecto, finalmente, obtuvo sanción en Senado en abril de 2006 y fue reglamentado en febrero de 2007.

En resumen, lo desarrollado en esta sección manifiesta que la confrontación de intereses en el Congreso argentino estuvo en las diferentes concepciones sobre cómo desarrollar esta industria. En este sentido, una de ellas fue favorable a la implementación de beneficios fiscales e impositivos; y la otra apoyaba un proyecto sin beneficios fiscales e impositivos. En ambos casos, se afectaba directamente a la configuración de un mercado interno. Asimismo, lo analizado sugiere tener en cuenta que existieron casos de sobrerepresentación del sector aceitero. Hay que añadir que el proyecto con beneficios fiscales 
e impositivos perseguidos por la Asociación Argentina de Biocombustibles e Hidrógeno (AABH), junto al despacho del Senador Falcó (UCR-Río Negro) tuvo un rol significativo en su promoción hasta que confrontaron con los intereses del Ministerio de Economía para impulsarlos sin dichos incentivos.

\section{Disputas internas}

En febrero de 2007 se reglamentó una ley para regular el mercado interno de biocombustibles, según se refirió anteriormente. El rumbo que había tomando la política de este sector en Argentina generó disputas entre dos agencias descentralizadas del Estado argentino. Una de ellas fue el Instituto Nacional de Tecnología Industrial (INTI), que hoy se ubica en la órbita del Ministerio de Industria; y la otra, el Instituto Nacional de Tecnología Agropecuaria (INTA), organismo que depende del Ministerio de Agricultura, Ganadería y Pesca de la Nación.

En esta sección, se analiza el posicionamiento de ambas instituciones respecto de la dimensión ambiental de este modelo de desarrollo, su vinculación con otros actores y sus percepciones sobre las tendencias internacionales. Para la primera institución, se analiza la posición de su Presidente respecto de estos asuntos, Enrique Martínez. Y para la segunda, al referente del Programa Nacional de Bioenergía del INTA, Jorge Hilbert. Éstos fueron seleccionados por haber participado en este proceso de discusiones en el orden interno y en la construcción de esta alternativa energética. A tal efecto, se utilizaron documentos de posicionamiento institucional, publicados en el contexto de la discusión del orden interno respecto de los biocombustibles.

Desde el INTI, se cuestionó el modelo de desarrollo en biocombustibles. Su Presidente planteó que el balance ambiental de los biocombustibles (biodiesel y etanol) era negativo. Esta consideración no menor, le permitía plantear y abrir un debate más amplio orientado a involucrar a otras opciones energéticas alternativas. En un documento publicado en 2007 se manifestó a favor de descentralizar la producción y consumo de este tipo de energía a nivel interno:

No tiene igual promoción mediática ni en muchos casos institucional, por descentralizar las fuentes de energía, la producción de biodiesel para usarlo al ıо०\%, a escala de una chacra. Hay ya un amplio damero de opciones de generación y consumo descentralizados, que harían menos necesarios los sistemas de producción y distribución de alta concentración, como los actuales (Martínez 2007a). 
Estas ideas sobre el desarrollo de biocombustibles ubicaron al INTI en confrontación con otros actores del ámbito público y privados del orden doméstico. En el primer caso, se diferencia claramente de la posición adoptada por el INTA.

Si la ecuación energética no cierra a partir del etanol o cuando se hace a partir del maíz no hay que ser necios. Ahí no hay un negocio solamente. Si no hay generación neta de energía, es todo un negocio absurdo, pero además de eso tampoco hay que comprar alegremente alternativas como la que dolorosamente, cuando nos embarcamos en el análisis de alternativas para agrocombustibles, elige el INTA. Yo tengo mucho respeto por la gente del INTA y he participado de muchos paneles. Creo que hay gente muy seria, que ha estudiado mucho el tema, pero se ve obligada por su exposición ante los hombres de negocios del campo a inventar alternativas como la de la jatrofa (Martínez 2007b).

También, criticó a la Asociación Argentina de Biocombustibles e Hidrógeno $(\mathrm{AABH})$, entidad que fomentó el desarrollo de los biocombustibles en Argentina y que participó durante el proceso de sanción de la ley de biocombustibles.

Un organismo como el nuestro tendrá que buscar mejorar el caudal tecnológico de la sociedad en los temas que crea más convenientes, pero deberíamos detenernos un minuto a tener la mirada global, porque si nos quedamos en la mirada específica nos va a pasar lo que le pasa a Claudio Molina, que viaja al exterior y vuelve espantado porque el biodiesel es más barato que el aceite de soja. ¡Pobre Claudio! (Martínez 2007c).

Pasado al plano internacional, Enrique Martínez realizó una lectura crítica de la industria global de biocombustibles. Señaló que los productores agrícolas al garantizarse una nueva demanda mundial fueron los principales beneficiados, como ocurrió, por ejemplo, en Estados Unidos; y quienes necesitaron importar maíz para consumo humano fueron los perjudicados porque a nivel internacional, el maíz tenía un nuevo destino: su conversión energética. Desde su diagnóstico, esta situación del comercio internacional del mercado alimentario y energético, ocasionaba dos consecuencias concretas: I-aumento de precios de los alimentos; 2-la posibilidad que Estados Unidos se posicione como comprador dominante en toda la cadena del mercado mundial de etanol (Martínez 2007b). También, situó a esta cuestión en el marco de una problemática ambiental global, asociándolo directamente a los patrones de consumo de los más ricos. Y por último, lo conectó a otros aspectos que 
instalan desafíos como una mayor demanda de tierra para sostener una creciente producción de alimentos ante proyecciones de crecimiento poblacional (Martínez 2007c).

Desde el INTA el involucramiento en torno del desarrollo de energías alternativas no constituyó un fenómeno novedoso. Su desarrollo en el tiempo fue interrumpido por un conjunto de variables, algunas de mercado y otras socio-ambientales. Desde su concepción, incluían un abanico de alternativas energética, entre las cuales se encontraba el biodiesel (Entrevista a Jorge Hilbert, 7 de julio de 2008).

En marzo de 2008, el INTA publicó un documento institucional. A diferencia del INTI, no se cuestionó la dimensión ambiental del modelo de desarrollo en biocombustibles. En su lugar, desde el supuesto de la "abundancia” de recursos naturales del país, tomaron con preocupación el cuidado de ciertos aspectos ligados a balances energéticos, la conservación de la biodiversidad, así como también, el impacto sobre el agua y el suelo. Esta "agenda ambiental”, ¿en función de qué era importante? Este es un interrogante central para comprender la forma de concebir que esta institución tenía sobre este asunto. Este proyecto no estaba orientado a desarrollar un proceso de descentralización de la producción y consumo de los biocombustibles. En su lugar, la preocupación estaba puesta en mejorar la oferta exportadora del país:

Argentina posee las condiciones necesarias para generar parte de la biomasa que se requerirá a nivel mundial" es una frase elocuente, en este sentido... La producción actual de granos, aceites y proteína vegetal, ubica a nuestro país como uno de los líderes mundiales en su exportación. El aprovechamiento de esos recursos para su conversión en bioenergía así como otros productos como harinas proteicas, vegetales y animales generará la oportunidad de, exportar mayor valor agregado en un plazo casi inmediato. Al mejorar la oferta exportadora del país, se podrán ofrecer alternativas de mercado para propiciar un mayor nivel de actividad, con el propósito de incrementar competitividad, productividad, sostenibilidad y equidad en la producción agropecuaria (Instituto Nacional de Tecnología Agropecuaria 2008, 3-4).

Esta "vocación exportadora" de Argentina, por su disponibilidad en abundantes recursos naturales, proyectaba transformaciones en el uso y la finalidad de su producción. Desde esta concepción, la agricultura no solo producía solamente alimentos sino también, energía. Además, la silvicultura también se posicionaba como una fuente de materias primas para producir energía a través de los residuos forestales. Como esto generaría cambios en el orden interno, desde el INTA proyectaban planificar el uso del suelo. En este 
sentido, uno de sus objetivos era definir un mapa nacional para distinguir tipos de suelos disponibles y zonas agroecológicas. Incluso, consideraban necesario introducir una Evaluación de Impacto Ambiental (EIA), que asegurara que realmente estaba trayendo beneficios ambientales.

En su vinculación con otros actores, su estrategia fue bifronte. Por un lado, buscaba tener aliados estratégicos en el ámbito estatal para la elaboración de una estrategia de desarrollo. Su enfoque articulaba energía, alimentos y medio ambiente. Para el INTA, "la política de fomento para la generación de biocombustibles, a partir de materias primas agrícolas y forestales nacionales, deberá ser tomadas como un Proyecto-País en su conjunto, el cual se complementará con la estrategia de seguridad alimentaria (disponibilidad de alimentos) y la de convertir a Argentina en un relevante actor agroindustrial/ alimentario. Como un principio básico de este enfoque, se destaca la necesidad de que el uso de los recursos naturales, suelo y agua para la producción de bioenergía, no debería afectar su disponibilidad, ni entrar en competencia con la producción de alimentos para el consumo interno y de exportación" (Instituto Nacional de Tecnología Agropecuaria 2008, 5).

Otra estrategia consistió en fomentar acciones de cooperación internacional. En este documento se presentan algunos ejes fundamentales de desarrollo del Programa Nacional de Bioenergía. Hay uno de ellos que está definido como "investigación y desarrollo". Se informa que las actividades de esta institución estarán orientadas a desarrollar tecnología para lograr tener un aprovechamiento integral de la biomasa. En ese marco, aparece una vinculación institucional con Naciones Unidas, específicamente con una de sus agencias: la Organización de las Naciones Unidas para la Agricultura y la Alimentación (FAO). A pesar que no hay una mención explícita de sus vinculaciones internacionales, aquí se conecta con la dinámica de la política internacional. En este sentido, uno de los proyectos fue llamado "Mapeo de Oferta y Demanda Integrada de Dendrocombustibles", conocidos por su siglas en inglés "WISDOM", que significa "Woodfuel Integrated Supply/Demand Overview Mapping”. En este marco, se generó un documento con el objetivo de tener información disponible sobre cuánto y dónde se disponía de biomasa en Argentina. (Organización de las Naciones Unidas para la Agricultura y la Alimentación 2009).

Respecto de sus percepciones sobre las tendencias internacionales, algo de esto se adelantó cuando se abordó cómo concebían la dimensión ambiental sobre el modelo de desarrollo. En el documento en cuestión, está presente la idea de un cambio de paradigma energético que países industrializados estaban transitando, pasando de economías "fosilizadas" a otras "verdes". En el documento se señala que: "La bioenergía está llamada a cumplir un 
rol junto a otras fuentes no convencionales en el cambio, de una economía basada en los combustibles fósiles a otra basada en un abanico de fuentes. La agricultura y la silvicultura serán las principales fuentes de biomasa para elaborar bioenergía en diferentes vectores, como la leña, el carbón, briquetas, biogás, bioetanol, biodiesel y bioelectricidad, entre otros" (Instituto Nacional de Tecnología Agropecuaria 2008, 2). Nótese que desde esta concepción no se está haciendo referencia exclusivamente al biodiesel o el etanol. Lo que plantean es más amplio en términos de opciones energéticas. En esta descarbonización de la economía, la biomasa adquiere una importancia central al ensanchar las posibilidades de materias primas utilizables para la generación de energía. En definitiva, esto representaba generar transformaciones en el uso en la finalidad de los recursos naturales en Argentina.

Esta sección, en resumen, se analizó el posicionamiento del INTI e INTA mediante tres ejes de análisis: la dimensión ambiental en la industria de biocombustibles, su vinculación con otros actores y sus percepciones sobre las tendencias internacionales. Se destaca que estos actores mantuvieron formas antagónicas de posicionamiento. De ellas, la visión del INTA fue la que terminó proyectándose en la política exterior de Argentina hacia América Latina en biocombustibles. En este sentido, se avanzó en menor medida en el fomento de experiencias de cooperación para incentivar la producción y consumo de este tipo de energía en forma descentralizada y en pequeñas escalas.

\section{América Latina}

Casi en paralelo a estas discusiones, en diciembre de 2006, el Consejo del Mercado Común decidió aprobar un Memorandum de Entendimiento para crear un Grupo Ah Hoc en Biocombustibles y recomendó su firma entre las partes. Su objetivo era estimular tanto la producción como consumo de biocombustibles; dentro de sus intereses estaba fomentar la cooperación técnica entre las partes. La I reunión tuvo lugar en marzo de 2008. Entre las cuestiones que se decidieron se destaca el acuerdo para realizar un taller sobre aspectos técnicos referidos a las cualidades físico-químicas de los biocombustibles, así como también mapear las empresas que hacían investigación en cualquiera de los eslabones de la cadena de producción de biocombustibles en el MERCOSUR. Éste fue el comienzo de este espacio de integración regional.

Meses más tarde, el MERCOSUR comunicó su posición institucional frente a la polémica internacional relación entre alimentos y biocombustibles. Aquí, los Presidentes del MERCOSUR disociaron la conexión entre 
producción de biocombustibles e incremento del precio de los alimentos, así como también, se posicionaron antagónicamente a países desarrollados que utilizaban materia prima agrícola para producir energía. Al mismo tiempo, ratificaron el rumbo que la política regional estaba tomado: la energía era considerado como un recurso estratégico para el MERCOSUR. Esto quedó claro en el punto 36 del Comunicado, en la que: "reconocieron asimismo la importancia de promover el uso y la producción de biocombustibles como fuente de energía renovable y alternativa capaz de contribuir a la diversificación de la matriz energética regional. Asimismo, registraron con satisfacción los avances alcanzados en el ámbito del Grupo Ad Hoc sobre Biocombustibles (GAHB) y destacaron la importancia de la implementación del Plan de Acción del MERCOSUR para la Cooperación en Materia de Biocombustibles" (MERCOSUR 2008).

Retomando los avances del Grupo Ah Hoc en Biocombustibles, al final del período que se estudia, se produjo su V reunión en 20I0. De acuerdo a lo que se observa del Acta final, la sustentabilidad de los biocombustibles constituyó un asunto de preocupación para los estados miembros. En este sentido, como línea de acción futura definieron que deberían establecer conjuntamente un criterio de sustentabilidad ambiental para respaldar su producción. Asimismo, aparecieron dos cuestiones con un claro componente político. Decidieron que deberían establecer posiciones conjuntas antes de participar en foros internacionales, así como también, definieron que era necesario participar activamente en la Asociación Internacional de Bioenergía, una asociación compuesta por actores públicos y privados de diferentes partes del mundo.

Otro espacio en el ámbito de la integración regional es el Consejo Agropecuario del Sur (CAS), compuesto por Argentina, Bolivia, Brasil, Chile, Paraguay y Uruguay, con el objetivo de coordinar políticas públicas agropecuarias. Uno de sus Grupos de Trabajo era, precisamente, el de Bioenergía. El soporte técnico y operativo de sus actividades estuvo a cargo del Instituto Interamericano en Cooperación para la Agricultura (IICA) y la Secretaría del CAS. En la VIII Reunión Ordinaria, que tuvo lugar en noviembre de 2005, se insistió en que su creación debería ser a la brevedad y que debería estar coordinado por Brasil (Consejo Agropecuario del Sur 2005). Posteriormente, en diciembre de 2007 , se decidió que se trabajaría en forma complementaria con el Grupo Ad Hoc en Biocombustibles del MERCOSUR (Consejo Agropecuario del Sur 2007). En marzo de 2008, en el contexto de la suba de precios de los alimentos en el mercado internacional, la CAS emitió un comunicado ratificando el rumbo de la política regional. Consideraban que los países integrantes del CAS tenían disponibilidad suficiente de materia prima 
como para producir alimentos y energía. A diferencia del grupo especializado del MERCOSUR, su mensaje incluyó una mención especial a la agricultura familiar. Esta referencia es relevante porque manifiesta un proyecto diferente al del MERCOSUR, en el que la escala de producción sería mucho menor: el sujeto beneficiario serían cooperativas de pequeños productores (Consejo Agropecuario del Sur 2008).

En otro orden, Venezuela y Cuba mantuvieron una posición crítica frente a la firma del acuerdo de cooperación entre Estados Unidos y Brasil para impulsar el desarrollo de la producción de biocombustibles en el continente americano, principalmente en América Central. En este contexto, se realizó la Cumbre Energética Sudamericana en Venezuela. Fue realizado en abril de 2007, en el marco de la Comunidad Suramericana de Naciones. Aquí, se produjeron hechos de vital importancia para la integración latinoamericana. La Comunidad Suramericana de Naciones pasó a llamarse Unión de Naciones Suramericanas y también, se creó el Consejo Energético de Suramérica. En materia de biocombustibles, el conflicto regional se saldó y se orientó hacia el desarrollo de este tipo de energía: "impulsar el desarrollo de las energías renovables, ya que cumplen un papel importante en la diversificación de la matriz energética primera, la seguridad energética, la promoción del acceso universal a la energía y la preservación del medio ambiente" (Comunidad Suramericana de Naciones 2007).

Tres años más tarde, se registraron avances. En la Cumbre extraordinaria de 20 Io en Los Cardales (Argentina), el Consejo Energético Suramericano aprobó una serie de documentos, producto de las reuniones que mantuvieron desde su creación como Consejo. Lo importante aquí es la elaboración de los lineamientos de la Estrategia Energética Suramericana y del Plan de Acción para la Integración Energética Regional, así como también, el establecimiento de la estructura del Tratado Energético Suramericana (Unión Suramericana de Naciones; Organización Latinoamericana de Energía 20I2, I5-16). En términos concretos, algunos de los criterios rectores que fueron definidos regionalmente fueron: asegurar el abastecimiento energético en la región; promover el intercambio energético regional; fortalecer la infraestructura energética regional; incentivar las acciones de cooperación entre empresas estatales de hidrocarburos; propiciar el intercambio y transferencia de tecnologías; y planificar regionalmente el uso de la energía. En este marco, definieron un plan de acción por cada tipo de energía, junto a un detallado número de actividades. En lo que se refiere a energías renovables, hay una referencia específica a los biocombustibles, en la que tienen como objetivo promover el uso y la producción de biocombustibles para diversificar la matriz energética regional (Unión Suramericana de Naciones; Organización Latinoamericana de Energía 20I2, I5-30). 


\section{Conclusiones}

En el marco de los estudios sobre política exterior, este trabajo se concentró en la política exterior reciente de Argentina y particularmente, en las relaciones entre orden interno y política exterior. Más concretamente, se analizó cómo fue posible la construcción del apoyo político doméstico de la política exterior de Argentina hacia América Latina en biocombustibles.

Como estrategia de abordaje, se seleccionaron dos ámbitos diferenciados y relevantes que sirvieron como fundamentos de la política exterior argentina, uno el legislativo nacional y el otro, el científico-técnico. En el primero, se analizaron las posiciones de actores en el marco de discusiones legislativas sobre un proyecto de Ley que terminó siendo, modificaciones mediante, la ley que actualmente regula en Argentina la producción y consumo en el mercado interno de biocombustibles. En el segundo, se avanzó sobre la polémica entre dos agencias especializadas del estado argentino: el INTA y el INTI. Por último, se analizó la política exterior de Argentina hacia América Latina. Se concluye, a partir de lo analizado y desarrollado en cada una de las secciones, que el apoyo político doméstico fue uno de los pilares de la política exterior argentina hacia América Latina en biocombustibles, durante los gobiernos de Néstor Kirchner (2003-2007) y Cristina Fernández (2007-20II).

Los alcances de estas conclusiones permiten corroborar algunos aspectos del diagnóstico realizado por otros autores, que investigaron el mismo tema y al mismo tiempo, permiten señalar nuevos aspectos. De acuerdo a lo observado por Miranda, en la toma de decisiones en Argentina, las decisiones en política exterior permanecieron concentradas en el Ejecutivo, es decir, la Cancillería y el Ejecutivo no abrieron el juego a que otros actores estatales y no estatales participaran durante el proceso. En este sentido, la política exterior de Argentina hacia América Latina en biocombustibles puso en manifiesto esta dinámica. Por último, es necesario agregar que si bien la investigación realizada no se concentró en los cambios o ajustes en política exterior y en su interrelación con los factores domésticos como lo hizo Busso, lo que sí si sugiere este trabajo es la existencia de fundamentos internos de la política exterior que permite trazar continuidades entre el orden interno y los lineamientos de la política exterior argentina hacia la América Latina, en materia de biocombustibles. 


\section{REFERÊNCIAS}

Busso, Anabella. 20I4. "Los vaivenes de la política exterior argentina redemocratizada (1983-2013). Reflexiones sobre el impacto de los condicionantes internos." Estudios Internacionales I77: 9-33.

Cámara de Senadores de la Nación. 2006. "Versión Taquigráfica - Sesión Ordinaria, I9 de abril de 2006 ", ig de abril. Acceso io de noviembre. http://www.senado.gov.ar/parlamentario/sesiones/busqueda

Campos, Miguel. 2oro. "La llegada definitiva de las energías limpias." Clarín, 30 de octubre. Acceso Io de noviembre, 20I4. http://edant.clarin.com/ suplementos/rural/2004/10/30/r-oiıio.htm

Clarín. 2005. "Con el tanque aún vacío." Clarín, 7 mayo. Acceso ro de noviembre, 20I4. http://edant.clarin.com/suplementos/ rural/2005/05/07/r-0020I.htm

Consejo Agropecuario del Sur. 2005. "Declaración de Ministros. VIII Reunión Ordinaria de Ministros.", is de noviembre. Acceso io de noviembre. http://www.consejocas.org/index.php/cas/reuniones-decas/reuniones-ordinarias

2007. "Declaración de Ministros. XIII Reunión Ordinaria de Ministros."

3 de diciembre. Acceso io de noviembre. http://www.consejocas.org/ index.php/cas/reuniones-de-cas/reuniones-ordinarias

_ 2008. "Contribuciones para una política agrícola regional en agroenergía, Grupo sobre Políticas Públicas en Agroenergía (GT6) - Red de Coordinación de Políticas Agropecuarias." http://agris.fao.org/agrissearch/search.do?recordID=AR2008000234

Comunidad Suramericana de Naciones. 2007. "Declaración de Margarita. Construyendo la integración energética del sur", abril. Acceso io de noviembre. http://unasur.webcindario.com/documentos.html

Cronista.com. 2006. "Cuatro leyes económicas son ahora prioridad en Diputados." Cronista, 26 de febrero. Acceso ro de noviembre. http:// www.cronista.com/impresageneral/Cuatro-leyes-economicas-sonahora-prioridad-en-Diputados-20060227-0033.html

Duroselle, Jean-Baptiste. I988. Todo imperio perecerá. Teoría sobre las relaciones internacionales. México: Fondo de Cultura Económica.

Figari, Guillermo. I993. Pasado, presente y futuro de la política exterior argentina. Buenos Aires: Editorial Biblos.

Gourevitch, Peter. I978. "The Second Image Reversed: The International Sources of Domestic Politics.”. International Organization 32 (4): 88I- 
892.

Instituto de Tecnología Agropecuaria. 2008. Programa Nacional de Bioenergía: Posicionamiento Institucional.

Instituto Nacional de Estadísticas y Censos. 20II. "Comercio exterior argentino 2010.” Acceso Io de noviembre. http://www.indec.mecon. ar/nuevaweb/cuadros/i9/com_ext_anu_io.pdf

La Política On Line. 2009. "Barañao desmiente estudio contra el glifosato: No es del Conicet.", I de mayo. Acceso Io de noviembre, 20I4. http://www. lapoliticaonline.com/nota/35858/

Martínez, Enrique. 2007a. "ENERGÍA + MEDIO AMBIENTE + ALIMENTOS: un humilde llamado de atención”, I7 enero. Acceso ro de noviembre, 20I4. http://www.inti.gov.ar/pdf/energia_medioambiente_alimentos. pdf

_ 2007b. "Etanol. ¿Oportunidad de qué?” Abril. Acceso ro de noviembre, 2014. http://www.inti.gov.ar/sabercomo/sc5I/intir.php

_ 2007c. "Reflexiones y Perspectivas sobre el papel de los Agrocombustibles en la Argentina", 5 de diciembre. Acceso ro de noviembre, 20I4. http:// www.iade.org.ar/modules/noticias/article.php?storyid=225I

Mercosur. 2008. "Comunicado conjunto de los Presidentes del MERCOSUR. XXXV Reunión del Consejo del Mercado Común”, i de julio. Acceso io de noviembre. https://mrecic.gov.ar/node/33045

Marín, Ana; Pérez Constanzó, Gloria. 20ıı. "Complejo Oleaginoso, Ministerio de Economía de Argentina. Subsecretaría de Programación Económica.” Acceso ro de noviembre http://www.mecon.gov.ar/peconomica/docs/ Complejo_Oleaginoso.pdf

Miranda, Roberto. 200I. "El eje doméstico de las cuestiones externas de la Argentina: el caso del Mercosur.” Invenio 4, (7): 99-156.

Molina, Claudio. 2004. "Energía limpia, empleo y desarrollo." Clarín, 4 de diciembre. http://edant.clarin.com/suplementos/ rural/2004/12/04/r-0040I.htm

Organización de las Naciones Unidas para la Agricultura y la Alimentación. 2009. "Análisis del Balance de Energía derivada de Biomasa en Argentina. Informe Final.” Acceso ro de noviembre. http://64.76.I23.202/ probiomasa/_pdf/Balance_de_Energia.pdf

Página 12. 2009. "El tóxico de los campos." Página 12, I3 de abril. Acceso Io de noviembre, 20I4. http://www.paginas2.com.ar/diario/ elpais/I-I23III-2009-04-I3.html

Putnam, Robert. I988. "Diplomacy and Domestic Politics: The Logic of Two- 
Level Games." International Organization 42: 427-460.

Rulli, Jorge. 2009. Pueblos Fumigados. Los efectos de los plaguicidas en las regiones sojeras. Buenos Aires: Editorial del Nuevo Extremo.

Scioli, Daniel. 2004. "Una política de biocombustibles." Clarín, 3 de julio. http://edant.clarin.com/suplementos/rural/2004/07/03/r-0200I.htm

Secretaría de Ambiente y Desarrollo Sustentable. 2008. "El avance de la frontera agropecuaria y sus consecuencias". Acceso io de noviembre. http://www.grr.org.ar/sym/avance_soja.pdf

Seitz, Ana. 2oro. "Integración Latinoamericana-Caminos, dilemas y desafíos." Ponencia presentada a la Jornada de la Red de Integración Latinoamericana (REDILA), Mendoza.

Unión de Naciones Suramericanas; Organización Latinoamericana de Energía. 20I2. "UNASUR: un espacio que Consolida la Integración Energética." Acceso to de noviembre. http://www.olade.org/es/ publicaciones/unasur-espacio-que-consolida-la-integracion

Urquía, Rubén. 2005. "Biocombustibles, una exigencia." Clarín, i9 de noviembre. Acceso to de noviembre. http://edant.clarin.com/ suplementos/rural/2005/II/I9/r-0280I.htm

van Klaveren, Alberto. I984. "El análisis de la política exterior latinoamericana: perspectivas teóricas." En Entre la autonomía y la subordinación. Política exterior de los países latinoamericanos, editado por Muñoz, Heraldo; Tulchin, Joseph. Buenos Aires: Editorial GEL.

\section{RESUMO}

El apoyo político doméstico fue uno de los pilares de la política exterior argentina en biocombustibles hacia América Latina, durante los gobiernos de Néstor Kirchner (2003-2007) y Cristina Fernández (2007-2011).

\section{PALAVRAS-CHAVE}

Política Exterior; Biocombustibles; Medio Ambiente.

Recebido em 6 de setembro de 2013. Aprovado em 13 de abril de 2015. 